\title{
Extraction and Characterization of Bagasse Fibres from Sugar Cane (Saccharum officinarum) for Incorporation into a Mortar
}

\author{
Tchotang Theodore1, Carlos Mozer ${ }^{1,2}$, Pondi Joseph ${ }^{1,2}$, Jeme Njie², Nfor Clinss, ${ }^{1,2}$, Ze Eric Parfait ${ }^{1,2}$, \\ Souck Joseph Loic ${ }^{1,2}$ \\ ${ }^{1}$ Laboratory of Engineering Civil and Mechanical, Department of Industrial and Mechanical Engineering, University of Yaoundé I, \\ Yaoundé, Cameroon \\ ${ }^{2}$ Local Materials Promotion Authority (MIPROMALO), Yaoundé, Cameroon \\ Email: yannickpondi@gmail.com
}

How to cite this paper: Theodore, T., Mozer, C., Joseph, P., Njie, J., Clins, N., Parfait, Z.E. and Loic, S.J. (2020) Extraction and Characterization of Bagasse Fibres from Sugar Cane (Saccharum officinarum) for Incorporation into a Mortar. Open Journal of Applied Sciences, 10, 521-533.

https://doi.org/10.4236/ojapps.2020.108036

Received: July 11, 2020

Accepted: August 8, 2020

Published: August 11, 2020

Copyright $\odot 2020$ by author(s) and Scientific Research Publishing Inc. This work is licensed under the Creative Commons Attribution International License (CC BY 4.0).

http://creativecommons.org/licenses/by/4.0/

\begin{abstract}
The paper reported a comparative study of the methods of extraction of vegetable fibres encountered in the literature; three main ones was chose, namely: combing, retting with pre-treatment of the bagasse in salt and distilled water, and Chemical extraction at three concentration levels of soda $(2 \mathrm{~N}, 1 \mathrm{~N}, 0.1 \mathrm{~N})$ with pre-treatment of bagasse with salt water and distilled water. After extracting the fibres using these methods, it appeared that the natural methods (retting and combing) have a higher yield of around $70 \%$ compared to the chemical method which has a low yield of around $40 \%$. The fibres obtained by the chemical extraction method (1N-BPD) had the best characteristics.
\end{abstract}

\section{Keywords}

Bagasse, Characterization, Elaboration, Extraction, Fibre

\section{Introduction}

Natural fibres are very popular in this century in the development of new building materials with lower environmental impact. Several researchers have worked already on this type of material and have obtained satisfactory results. Plant fibres in mortar help limit the spread of cracks [1]. Thus, banana fibres in a bio composite increase its durability [2]. Mazhoud [3] and Chabannes [4] have proven the hygrothermal efficiency of hemp concrete. Osseni [5] demonstrated that mortars containing banana fibres are a good thermal insulator with their 
low thermal conductivity. Certain results obtained for composite materials incorporated with vegetable fibres show a modification of the mechanical behavior of the material [1]. Thus, the addition of banana fibres to compressed earth blocks has improved its mechanical properties [6] [7]. Sawsen et al. [8] have shown that treated linen fibres improve the mechanical characteristics of the mortar.

Till date, the bagasse fibre of sugar cane has few direct applications in ecomaterials. Obtaining these fibres and using them in the area of composites are currently in the preliminary research and development stage. The cultivation of sugar cane in the Great South of Cameroon and particularly in the locality of Mbandjock and Koteng is mainly intended for the manufacture of rum and sugar. These industries generate a natural resource, rich in fibres: bagasse. It is generally used as fuel to power up boilers in processing plants. Due to its fibrous potential, other avenues for revaluating are being addressed, with the advantage of its availability and biodegradability. Opportunities for socio-economic development in a sugar cane producing country, with nearly 20,000 hectares (ha) [9] of sugar cane plantations, require studies upstream, analyses, pilot trials, etc. The establishment of a valorisation/revaluation sector for cane bagasse is based on knowledge of the raw material, as well as on the mastery of processing methods.

Bagasse is made up of fibrous residues from the crushing of the cane. It represents $30 \%$ of the weight of the cane cut and brought to the factory [9]. However, almost all of the bagasse today is either thrown into the wild as waste, or used as fuel in sugar plants to heat ovens and for the production of electricity. This recovery of bagasse creates a very significant loss of fibres from the bark which can be valuated this is why, this work propose, to extract and characterize this fibre so that it can be incorporated into a mortar for construction.

\section{Materials and Methods}

\subsection{Origin and Preparation of Bagasse}

Cameroon presents several varieties of sugar cane cultivated throughout the national territory. It is difficult to follow each geographical area according to the varieties, and it has been established that the chemical and histological compositions of the main chemical compounds do not vary significantly from one variety to another [10].

\subsection{Preparation of the Material}

From the cane bark, harvested in the fields, the bagasse must be separated from the stems. Figure 1 shows the appearance of the materials used in this work.

The extraction methods developed will make it possible to move from virgin bagasse to fibres.

\subsection{Protocol for Extraction of Bagasse Fibres}

\subsubsection{Chemical Extraction}

Each test is carried out using bagasse extracted from sugar cane cut in the field, 
then treated at atmospheric pressure, with the following parameters:

- Soda concentrations: $0.1 \mathrm{~N} ; 1 \mathrm{~N} ; 2 \mathrm{~N}$;

- Solvents used: salt water and distilled water;

- Bath temperature: room temperature $\left(25^{\circ} \mathrm{C}\right)$;

- Agitation: manual.

The pre-treatment and extraction protocols were developed, according to Davina [11], then adapted for bagasse particles, with the preferential objective of long, fine fibres. The extraction was carried out following six different protocols, presented in Table 1.

The aspect obtained is presented in Figure 2.

It appears from Figure 2 that: the higher the concentration of soda, the more intense the color of the bath. This is mainly due to the amount of lignin extracted: the more intense the bath, the more lignin is extracted [11].

\subsubsection{Retting Out}

In this technique, the experimental protocol is simple: it is a question of introducing the fibres into a beaker containing a certain amount of water. In this work, two protocols presented in Table 2.
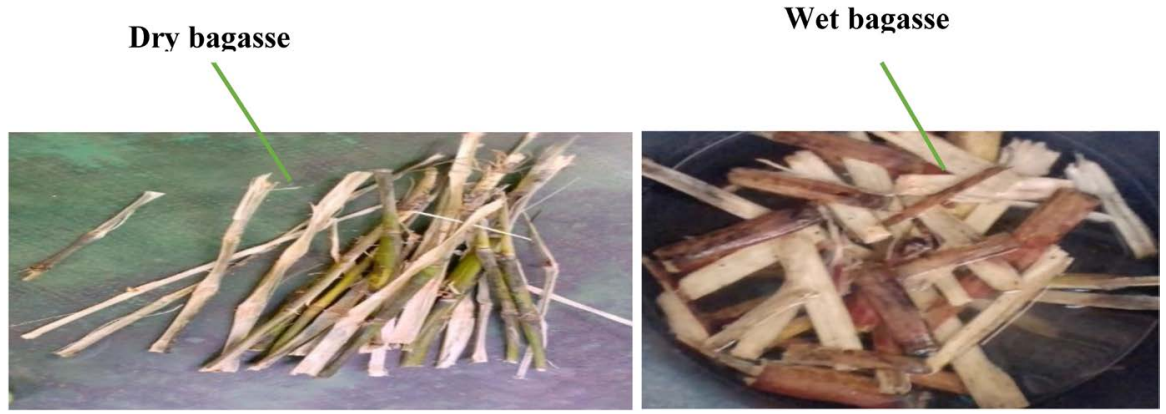

Figure 1. Virgin materials: bagasse.

Table 1. Chemical extraction conditions with soda.

\begin{tabular}{|c|c|c|c|}
\hline & Quantity of matter & $\begin{array}{l}\text { Amount of } \\
\text { soda }\end{array}$ & Classification \\
\hline Extraction 1 & $\begin{array}{l}1 \text { gram of virgin } \\
\text { bagasse }\end{array}$ & $100 \mathrm{ml}$ & $\begin{array}{c}1 \mathrm{~N}-\mathrm{BPS} \text { : bagasse extracted with } 1 \mathrm{~N} \text { soda with } \\
\text { pre-hydrolysis with salt water }\end{array}$ \\
\hline Extraction 2 & $\begin{array}{l}1 \text { gram of virgin } \\
\text { bagasse }\end{array}$ & $100 \mathrm{ml}$ & $\begin{array}{l}1 \mathrm{~N} \text {-BPD: bagasse extracted with } 1 \mathrm{~N} \text { soda with } \\
\text { pre-hydrolysis with distilled water }\end{array}$ \\
\hline Extraction 3 & $\begin{array}{l}1 \text { gram of virgin } \\
\text { bagasse }\end{array}$ & $100 \mathrm{ml}$ & $\begin{array}{c}2 \text { N-BPS: bagasse extracted with } 2 \mathrm{~N} \text { soda with } \\
\text { pre-hydrolysis with salt water }\end{array}$ \\
\hline Extraction 4 & $\begin{array}{l}1 \text { gram of virgin } \\
\text { bagasse }\end{array}$ & $100 \mathrm{ml}$ & $\begin{array}{l}2 \text { N-BPD: bagasse extracted with } 2 \mathrm{~N} \text { soda with } \\
\text { pre-hydrolysis with distilled water }\end{array}$ \\
\hline Extraction 5 & $\begin{array}{l}1 \text { gram of virgin } \\
\text { bagasse }\end{array}$ & $100 \mathrm{ml}$ & $\begin{array}{l}0.1 \mathrm{~N}-\mathrm{BPS} \text { : bagasse extracted with } 0.1 \mathrm{~N} \text { soda } \\
\text { with pre-hydrolysis with salt water }\end{array}$ \\
\hline Extraction 6 & $\begin{array}{l}1 \text { gram of virgin } \\
\text { bagasse }\end{array}$ & $100 \mathrm{ml}$ & $\begin{array}{l}0.1 \mathrm{~N} \text {-BPD: bagasse extracted with } 0.1 \mathrm{~N} \text { soda } \\
\text { with pre hydrolysis with distilled water }\end{array}$ \\
\hline
\end{tabular}




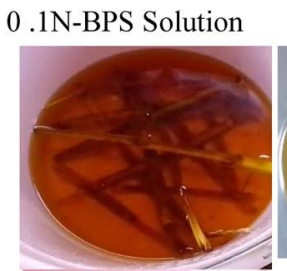

0.1N-BPD Solution

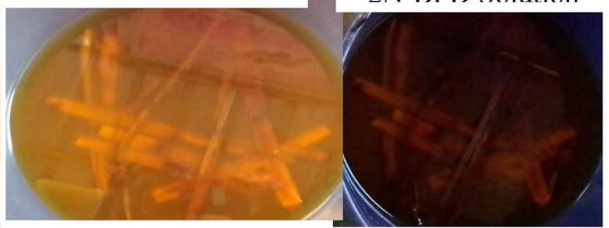

1N-BPD Solution

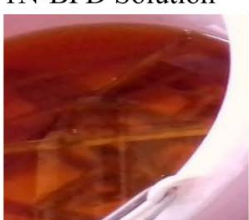

1N-BPS Solution

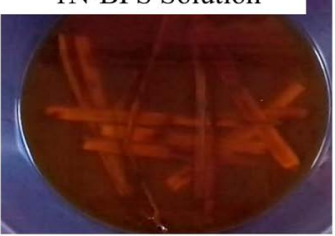

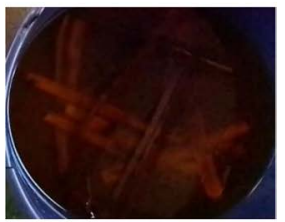

Figure 2. Aspect of chemical extraction solutions.

Table 2. Experimental protocol for retting.

\begin{tabular}{cccccc}
\hline Method & $\begin{array}{c}\text { Amount of } \\
\text { initial material }\end{array}$ & $\begin{array}{c}\text { Distilled } \\
\text { water }\end{array}$ & $\begin{array}{c}\text { Salt } \\
\text { water }\end{array}$ & Duration & Classification \\
\hline 1 & $\begin{array}{c}1 \text { gram of virgin } \\
\text { bagasse }\end{array}$ & $100 \mathrm{ml}$ & - & $\begin{array}{c}\text { One week } \\
(7 \text { days })\end{array}$ & $\begin{array}{c}\text { Retting-BPD: bagasse extracted by retting } \\
\text { with pre-hydrolysis with distilled water }\end{array}$ \\
& $\begin{array}{c}1 \text { gram of virgin } \\
\text { bagasse }\end{array}$ & - & $100 \mathrm{ml} \begin{array}{c}\text { One week } \\
\text { (7 days) }\end{array}$ & $\begin{array}{c}\text { Retting-BPS: bagasse extracted by retting } \\
\text { with pre-hydrolysis with salt water }\end{array}$ \\
\hline
\end{tabular}

\section{Extraction by combing}

In this technique, a wire brush used; the extraction principle here consists of brushing the inside of the bagasse walls in order to obtain the fibres. The wire brush passed on the internal part of the bagasse bark which allows the fibres to dissociate from this internal wall and then collected.

\subsection{Method of Characterizing Bagasse Fibres}

\subsubsection{Method of Determination of Fibre External Diameter}

To determine the external average diameter of the fibres, an optical microscope was used and two glass slides between which the fibre was placed on the graph paper.

The microscope being connected to the computer and using the screen allows us to visualize the morphological aspect of the fibre in Figure 3.

\subsubsection{Méthodes de Caractérisation Physique}

\section{1) Determination of the apparent density}

Density is an important data since it makes it possible to define the rate of reinforcement necessary for the resistance and the rigidity of the desired final composite [2]. The apparent density is calculated by measuring the mass, length and diameter of several fibres. To have the masses and lengths of the fibres, respectively, a $10^{-4}$ precision balance of Sartorius brand and a digital calliper was used (Figure 4).

The apparent density is obtained using the following formula:

$$
\rho=\frac{m}{v}
$$




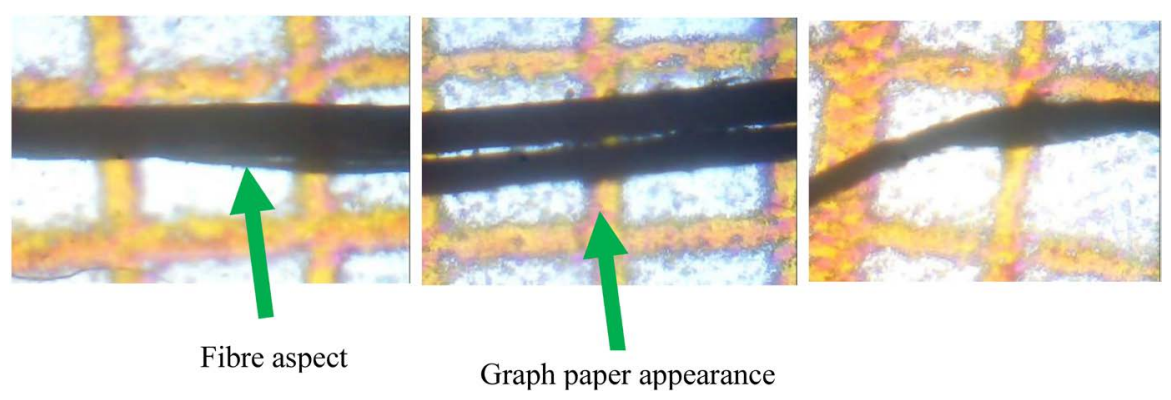

Figure 3. Morphological aspect of some fibers observed under the microscope.

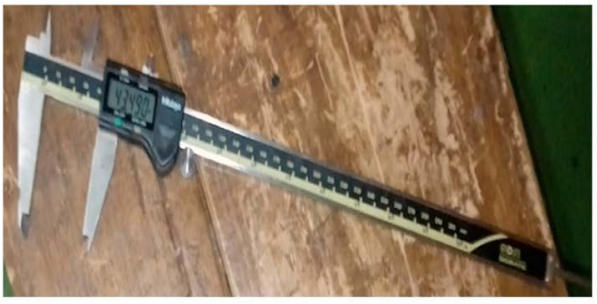

Digital calliper

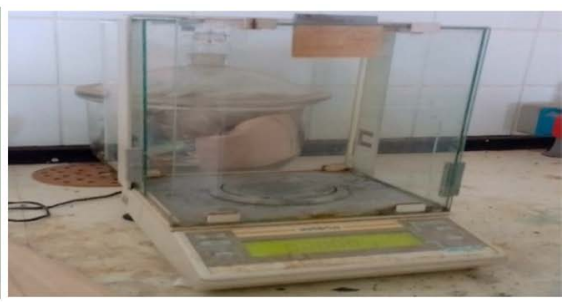

Precision Sartorius scale $10^{-4}$

Figure 4. Material for density determination

With: $\rho$ apparent volumetric mass in $\mathrm{g} / \mathrm{cm}^{3}$,

$m$ : fibre mass $(\mathrm{g})$,

v. fibre volume $\left(\mathrm{cm}^{3}\right)$.

\subsubsection{Hygroscopy of Bagasse Fibres}

\section{1) Recovery rate}

The recovery rate is defined as the amount of water present in the air that can absorb 100 grams of dry matter under well-determined hygrometric conditions [11]. This test was carried out according to the gravimetric method Based on the standard NF G08-001-4. The formula giving the recovery rate is as follows:

$$
R \%=\frac{M h-M s}{M s} * 100
$$

Mh: the wet mass under the given humidity and temperature conditions (in grams);

$M s$. dry mass (in grams).

\section{2) Water content}

The water content or humidity of a material is defined as the amount of humidity contained in 100 grams of wet matter under well-defined climatic conditions [11]. This test was carried out according to the gravimetric method Based on the standard NF G08-001-4. The equation giving the water content is as follows:

$$
Q \%=\frac{M h-M s}{M h}
$$

\subsubsection{Methods of Mechanical Characterisation}

The tensile tests were carried out at the scientific and technical service center in Food Processing, Packaging, Environment and Textile (Celabor) in Herve in 
Belgium. The test conditions were as follows:

- Applied standard: DIN EN ISO 13934-1;

- Device: Zwick $10 \mathrm{kN}$ cell;

- Test speed: $100 \mathrm{~mm} / \mathrm{min}$;

- Distance between tools for initial position: $100 \mathrm{~mm}$.

\section{1) Experimental Protocol}

The method used is that of the conventional tensile test. The sugar cane bagasse fibre is glued to paper to ensure its linearity and placed between the fixed and movable jaws of the mechanism. The central unit makes it possible to collect the data of the standard force until rupture as a function of the elongation. The Figure 5 presents the appearance of the stress-Elongation curves as a function of the extraction method.

2) Method for determining the mechanical properties of bagasse fibres Figure 5 below shows the appearance of the stress-strain curves as a function of the extraction method. From the measured force/displacement data at each instant of a tensile test, we calculate the following:

- Maximum standard stress

$$
\sigma_{\max }=\frac{F_{\max }}{S_{0}}
$$

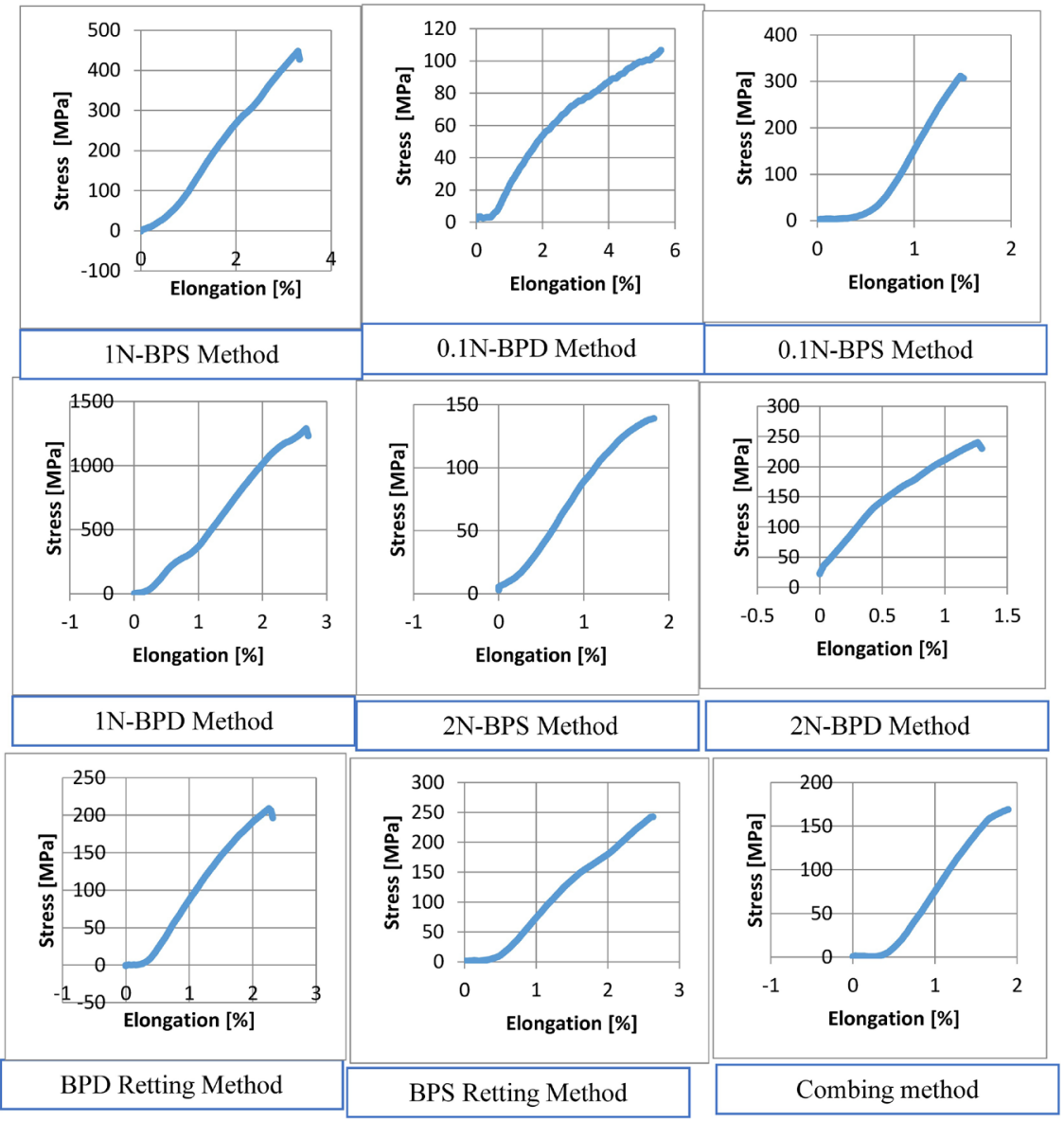

Figure 5. Stress-Elongation curves for each extraction method. 
- Standard failure stress

$$
\sigma_{r}=\frac{F_{r}}{S_{0}}
$$

\section{- Young's Modude}

With:

- $\sigma$ : stress in $\mathrm{MPa}$;

- $F$ : strength in $\mathrm{N}$;

- $S_{0}$ : Initial fibre section in $\mathrm{mm}^{2}$;

- $\varepsilon$ strain in \%.

\section{Results and Discussions}

\subsection{Hygrometric Properties of Bagasse Fibres}

The water absorption rate varies generally from $6.04 \%$ to $10.18 \%$. It varies from one process to another. It is maximum $10.18 \%$, for retting with bagasse pre-hydrolyzed in salt water, and minimal (6.04\%) for the chemical extraction process $(2 \mathrm{~N})$ with bagasse pre-hydrolyzed with distilled water (Figure 6).

The conclusion is that, the rusting extraction process with BPS allows for maximum water retention in the fibres. The water absorption rate varies from $6.52 \%$ to $11.32 \%$. It varies from one process to another; it is maximum $11.32 \%$, for retting with bagasse pre-hydrolyzed in salt water, and minimal 6.52 for the chemical extraction process $(2 \mathrm{~N})$ with bagasse pre-hydrolyzed with distilled water.

The conclusion is that, the rusting extraction process with BPS allows maximum water absorption.

\subsection{Physical Properties of Bagasse Fibres}

\section{Determination of the Average Diameter of Bagasse Fibres}

Pending the development of more sophisticated methods, this is the method by microscopic observation which was chosen for this work. To finally find the average value of the diameter of the sugar cane bagasse, we will use a recommended statistical tool: the normal law because it is the one that best covers such a distribution.

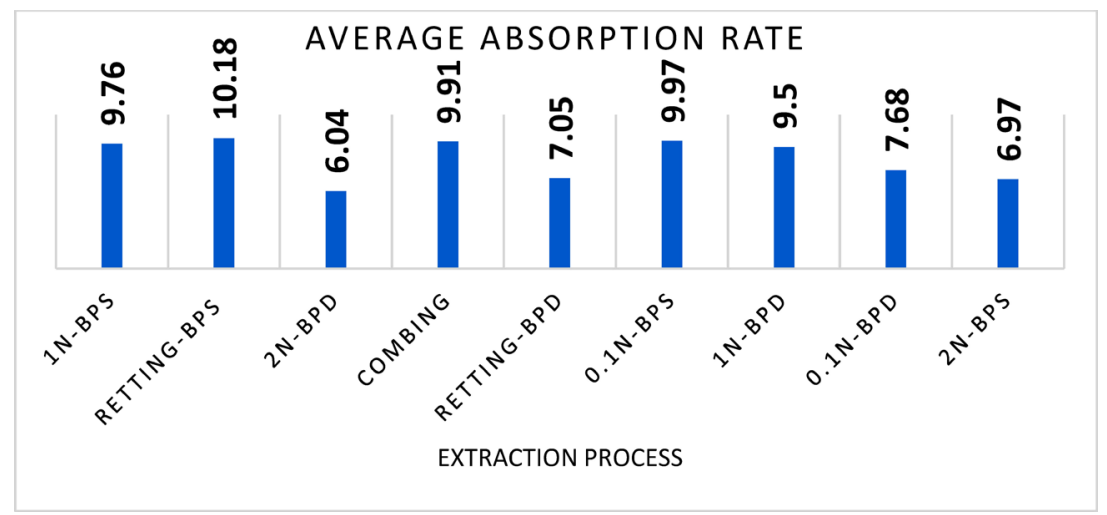

Figure 6. Evolution of the absorption rate depending on the process. 
It appears from Figure 7 that the average value of the outside diameter of the bagasse fibres is around: $0.19 \mathrm{~mm}$ with a standard deviation of $0.05 \mathrm{~mm}$.

Figure 8 allows us to see that the retting extraction process with BPS allows maximum water absorption.

1) Determination of the density of bagasse fibres

The average densities found by extraction method are shown in Figure 9 below:

It appears from Figure 9 that, the chemical extraction process has a higher density $\left(2.03 \mathrm{~g} / \mathrm{cm}^{3}\right)$ compared to natural processes (retting and combing) whose density is of the order $1.2 \mathrm{~g} / \mathrm{cm}^{3}$.

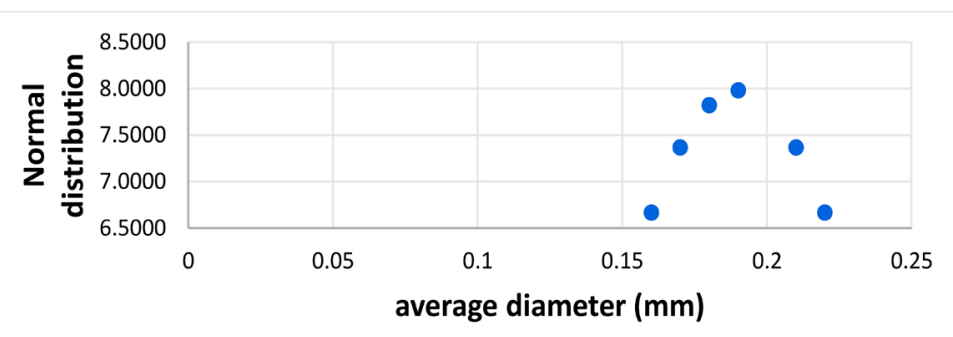

Figure 7. Evolution according to the normal law of fibre diameters.

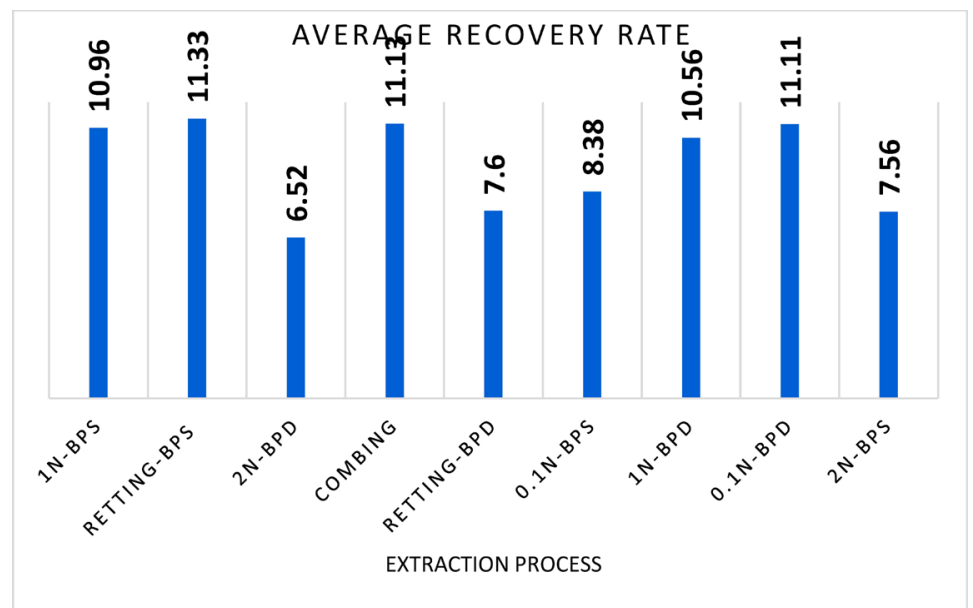

Figure 8. Evolution of the recovery rate depending on the process.

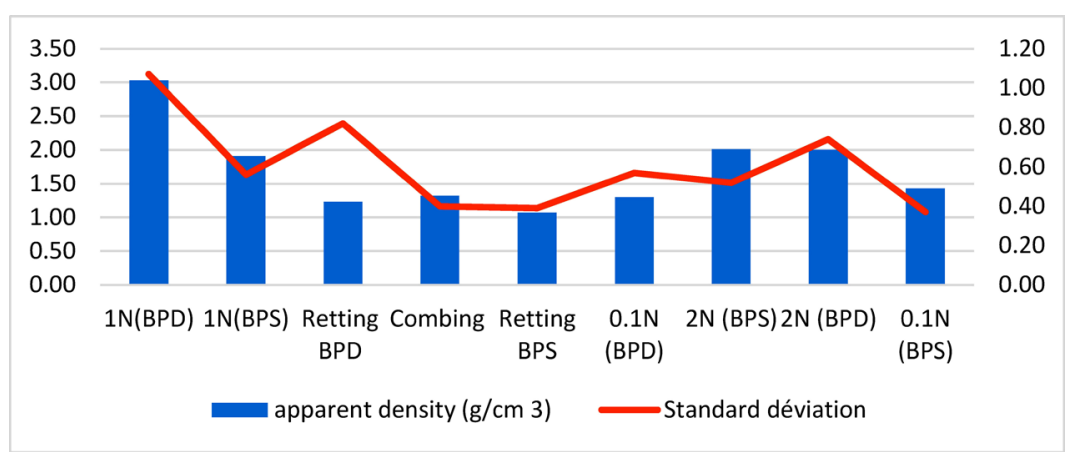

Figure 9. Comparison of the results on the densities of the fibers according to the processes. 


\subsection{Mechanical Properties in Tension of Bagasse Fibres}

\subsubsection{Comparison of Extraction Processes}

\section{1) Young's Module}

The histogram in Figure 10 below shows the comparison of the Young's moduli obtained by different methods of fibre extraction.

It can be seen from this graph that the chemical extraction method (1N-BPD) has the highest Young's module (53.17 GPa); and the chemical extraction method (0.1 N-BPD) has the lowest Young's module (1.9 GPa).

\section{2) Stress at rupture}

The histogram in Figure 11 below shows the comparison of the breaking stress obtained by different methods of fibre extraction.

The graph in Figure 12 shows that: the chemical extraction method (1 $\mathrm{N}-\mathrm{BPD})$ has the highest breaking stress (1231.83 MPa). Therefore, fibres treated with soda are more resistant than untreated fibres. This conclusion was also

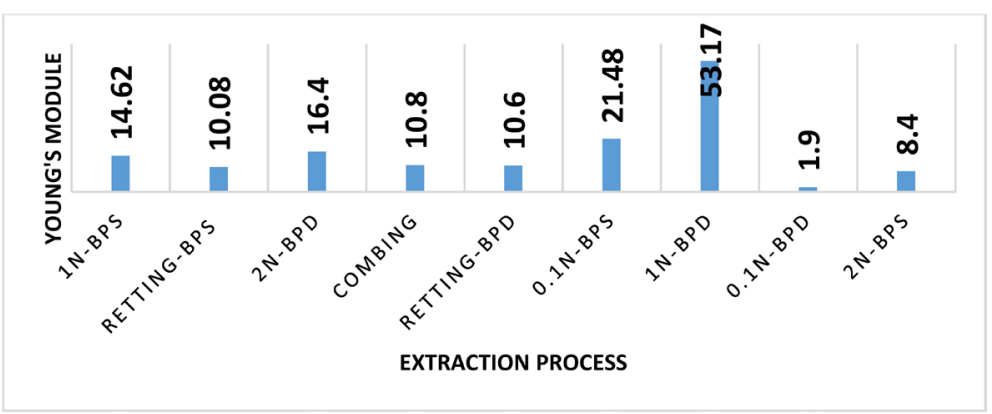

Figure 10. Comparison of Young's module.

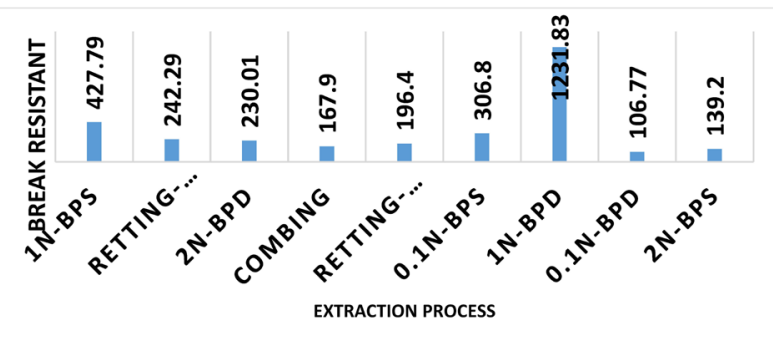

Figure 11. Comparison of rupture stress of the processes.

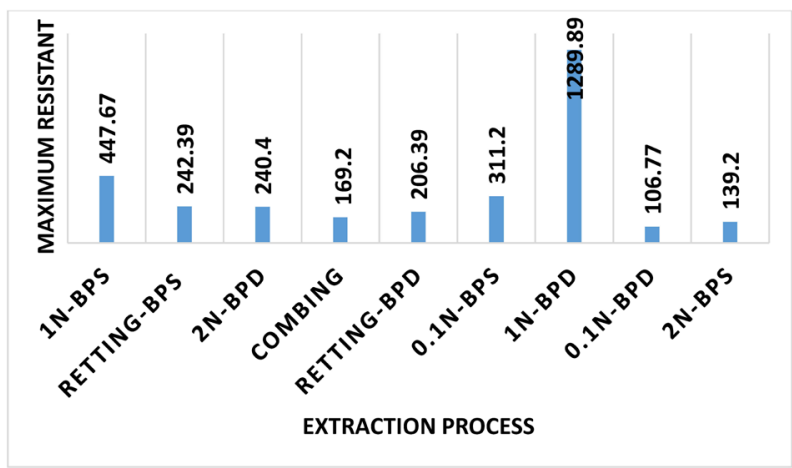

Figure 12. Comparison of maximum stress of the processes. 
observed by Sedan [12].

\section{3) Maximum stress}

The histogram in Figure 12 below shows the comparison of the maximum resistances obtained by different methods of fibre extraction.

The graph in Figure 13 shows that: the chemical extraction method (1 NBPD) has the highest breaking stress (1289.89 MPa). It was noticed that when soda is too concentrated, for example the case of $2 \mathrm{~N}$, it almost destroys the structure of the fibre, making it less resistant mechanically. When there is also a low concentration of sodium hydroxide, for example the case of $0.1 \mathrm{~N}$, there is no great influence on the mechanical properties.

\section{4) Elongation at rupture}

The histogram in Figure 13 below shows the comparison of the elongations at rupture point obtained by different methods of fibre extraction.

It appears from this graph that the chemical extraction method (0.1 N-BPD) has the highest elongation at break (5.6\%), and the chemical extraction method (2 N BPS) has the lowest elongation at break (1.8\%).

At the end of this analysis, we discovered that the best method that produces ductile fibres is the chemical extraction method (1 N-BPD). Because it permits generally to obtain the best mechanical characteristics. This result is also demonstrated for other vegetable fibres which when treated with $6 \% \mathrm{NaOH}$ and incorporated in a mortar, increase the flexural strength [12] and other properties like compressive strength of the mortar [12] [13] [14] [15]. Thus, the overall characteristics (mechanical, physical) retained for our bagasse fibres are shown in Table 3 below.

\subsubsection{Summaries of the Main Results}

In this section, the results from laboratory experiments was presented, and some

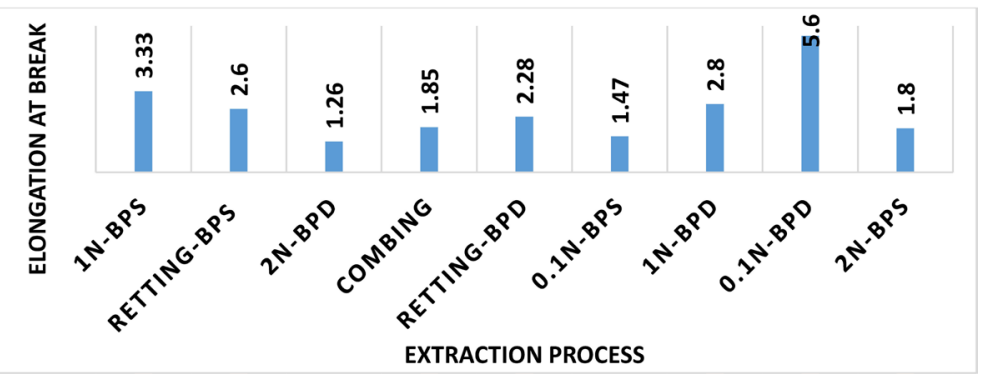

Figure 13. Comparison of the lengthening of the extraction processes.

Table 3. General data of the best extraction method.

\begin{tabular}{cccc}
\hline \multicolumn{2}{c}{ Mechanical characteristics } & \multicolumn{2}{c}{ Physical characteristics } \\
\hline Maximum stress (MPa) & 1289.89 & Density $\left(\mathrm{g} / \mathrm{cm}^{3}\right)$ & 2.03 \\
Breaking stress (MPa) & 1231.83 & Water content (\%) & 10.56 \\
Elongation at break (\%) & 2.8 & Recovery rate (\%) & 9.5 \\
Young's module (GPa) & 53.17 & & \\
\hline
\end{tabular}


conclusions have been drawn: The sugarcane bagasse fibres has a fine geometry compared to many fibres encountered in literature with an average diameter which is around $0.19 \mathrm{~mm}$. Its hygrometry (recovery rate and water content) is encouraging because it revealed that the bagasse fibres absorb less water (the water content and the recovery rate being $10.18 \%$ and $11.32 \%$ respectively) compared to many other vegetable fibres that have been incorporated into a mortar [16] [17]. The fibres obtained by the chemical extraction method (1 N-BPD) had the best characteristics. This result means that with this percentage of soda $(\mathrm{NaOH})$, the residual mechanical strength of the fibres increases. This was also mentioned by Toledo et al. [18]; this is all the more consistent because according to Van de Weyenberg et al. [19], the treatment of plant fibres with $\mathrm{NaOH}$ changes their structure.

This result could be exploited in the study of the durability of mortars in which bagasse fibres are introduced; as several authors have shown, in this case Sedan et al [12], plant fibres treated with $6 \% \mathrm{NaOH}$ are sufficient to improve the flexural strength of at least $39 \%$ of mortars in which these fibres are incorporated.

It should also be noted that the extraction methods used each have their advantages and disadvantages. Natural methods: Combing and retting have the advantage that they are less expensive, and do not require a lot of equipment and expertise to implement; but the fibres from these methods do not have the best characteristics. On the other hand, the chemical method with soda $(\mathrm{NaOH})$ is more expensive and requires more expertise than natural methods, but it allows to extract more fibres with the best characteristics.

\section{Conclusion}

We made a comparative study of the methods of extraction of vegetable fibres encountered in the literature; we chose three main ones, namely: combing, retting with pre-treatment of the bagasse in salt and distilled water, and Chemical extraction at three concentration levels of soda $(2 \mathrm{~N}, 1 \mathrm{~N}, 0.1 \mathrm{~N})$ with pretreatment of bagasse with salt water and distilled water. After extracting the fibres using these methods, it appeared that the natural methods (retting and combing) have a higher yield of around $70 \%$ compared to the chemical method which has a low yield of around $40 \%$. For the physical characterization, it should be noted that the average diameter of the bagasse fibres is around $0.19 \mathrm{~mm}$. The water content and the maximum recovery rate being $10.18 \%$ and $11.32 \%$ respectively. These values are average compared to the other vegetable fibres used for the preparation of composite materials. The fibres extracted with natural methods (retting and combing) had the best density around $1.23 \mathrm{~g} / \mathrm{cm}^{3}$. On the contrary, the fibres obtained using chemical methods have their turn around 2.03 $\mathrm{g} / \mathrm{cm}^{3}$. In terms of mechanical characterization, the fibres extracted using sodium hydroxide at a concentration of $1 \mathrm{~N}$ had the best properties of all the fibres extracted with a breaking stress of $1231.83 \mathrm{MPa}$ and a maximum stress of 1289.89 
MPa. By evaluating the physico-mechanical properties of the fibres for each extraction process, it appears that the fibres obtained by chemical extraction had the best characteristics.

\section{Conflicts of Interest}

The authors declare no conflicts of interest regarding the publication of this paper.

\section{References}

[1] Page, J. (2017) Formulation et caractérisation d'un composite cimentaire bio fibré pour des procédés de construction préfabriquée. PHD Thesis, University of Caen Normandie, Caen, 240 p.

[2] Sango, T., Yona, C.M.A., Duchatel, M.L., Ndikontar, A., Joly, K.M. and Lefebvre, N. (2018) Step-Wise Multi-Scale Deconstruction of Banana Pseudo-Stem (Musaacuminata) Biomass and Morpho-Mechanical Characterization of Extracted Long Fibres for Sustainable Applications. Industrial Crops and Products, 122, 657-668. https://doi.org/10.1016/j.indcrop.2018.06.050

[3] Mazhoud, B. (2017) Elaboration et caractérisation mécanique, hygrique et thermique de composites bio-sourcés. PHD Thesis, University of Bretagne, Loire, 212 p.

[4] Chabane, M. (2015) Formulation et étude des propriétés mécaniques d'agrobétons légers isolants à base de balles de riz et de chènevotte pour l'éco-construction. PHD Thesis, University of Montpellier, Montpellier, $226 \mathrm{p}$.

[5] Osseni, S.O. (2017) Formulation et caractérisation thermomécanique de mortiers renforcés par des fibres du tronc de bananier. PHD Thesis, University of AbomeyCalavi, Benin, 148 p.

[6] Amir, N., Abidin, Z.A.K. and Shiri, B.F. (2017) Effects of Fibre Configuration on Mechanical Properties of Banana Fibre/PP/MAPP Natural Fibre Reinforced Polymer Composite. Procedia Engineering, 184, 573-580.

https://doi.org/10.1016/j.proeng.2017.04.140

[7] Mostafa, M. and Uddin, N. (2016) Experimental Analysis of Compressed Earth Block (CEB) with Banana Fibers Resisting Flexural and Compression Forces. Case Studies in Construction Materials, 5, 53-63. https://doi.org/10.1016/j.cscm.2016.07.001

[8] Sawsen, C., Fouzia, K., Mohamed, B. and Moussa, G. (2014) Optimizing the Formulation of Flax Fiber-Reinforced Cement Composites. Construction and Building Materials, 54, 659-664. https://doi.org/10.1016/j.conbuildmat.2013.12.038

[9] Sugar Cane. 20 p. http://www.somdiaa.com/groupe/filiales/sosucam/

[10] AFNOR (1987) Textiles. Fibres et fils-Détermination de la masse commerciale d'un lot NF G08-001-4.

[11] Davina, M. (2013) Evaluation du potentiel fibreux et textile de la canne à sucre (Saccharum officinarum L.). PHD Thesis, University of Haute Alsace, Mulhouse, $187 \mathrm{p}$.

[12] Sedan, D., Pagnoux, C., Smith, A. and Chotard, T. (2008) Mechanical Properties of Hemp Fibre Reinforced Cement: Influence of the Fibre/Matrix Interaction. Journal of the European Ceramic Society, 28, 183-192. https://doi.org/10.1016/j.jeurceramsoc.2007.05.019

[13] Chafei, S., Khadraoui, F., Boutouil, M. and Gomina, M. (2014) Optimizing the 
Formulation of Flax Fiber-Reinforced Cement Composites. Construction and Building Materials, 54, 659-664. https://doi.org/10.1016/j.conbuildmat.2013.12.038

[14] Chafei, S. (2014) Influence de différents traitements sur les comportements rhéologiques et mécaniques d'un composite cimentaire mortier-fibres de lin. Thesis, University of Caen Basse-Normandie, Caen.

[15] Toledo Filho, R.D., Silva, A., Fairbairn, E.M.R. and Filho, A.M. (2009) Durability of Compression Molded Sisal Fiber Reinforced Mortar Laminates. Construction and Building Materials, 23, 2409-2420.

https://doi.org/10.1016/j.conbuildmat.2008.10.012

[16] Mc Govern, J.N. (1990) Fibers, Vegetable. In: Polymers. Fibers and Textiles, a Compendium, John Wiley and Sons, New-York, 412-430.

[17] Morton, W.E. and Hearle, J.W.S. (1986) Physical Properties of Textile Fibers. 2nd Edition, The Textile Institute \& Butterworth and Co., London, 170.

[18] Toledo Filho, R.D., Scrivener, K., England, G.L. and Ghavami, K. (2000) Durability of Alkali-Sensitive Sisal and Coconut Fibres in Cement Mortar Composites. Cement and Concrete Composites, 22, 127-143. https://doi.org/10.1016/S0958-9465(99)00039-6

[19] Van de Weyenberg, I., Chi Truong, T., Vangrimde, B. and Verpoest, I. (2006) Improving the Properties of UD Flax Fibre Reinforced Composites by Applying an Alkaline Fibre Treatment. Composites Part A: Applied Science and Manufacturing, 37, 1368-1376. https://doi.org/10.1016/j.compositesa.2005.08.016 